\title{
Exercise as Potential Therapeutic Target to Modulate Alzheimer's Disease Pathology in APOE \&4 Carriers: A Systematic Review
}

\author{
Sevilay Tokgöz · Jurgen A. H. R. Claassen
}

Received: July 16, 2020 / Published online: January 5, 2021

(C) The Author(s) 2021

\section{ABSTRACT}

Alzheimer's disease (AD) is a progressive neurodegenerative disease for which no effective treatment exists at present. Previous research has found that exercise reduces the risk of AD. Since the apolipoprotein E (APOE) $\varepsilon 4$ allele increases the risk of $\mathrm{AD}$ and is associated with faster disease progression than the other isoforms, we aimed to highlight the impact of exercise on AD pathology in APOE $\varepsilon 4$ carriers. This review focuses on the effect of exercise on cognitive function, dementia risk, amyloid- $\beta$ (AB) metabolism, lipid metabolism, neuroinflammation, neurotrophic factors and vascularization in APOE $\varepsilon 4$ carriers. We searched the literature in the PubMed electronic database using the following search terms: physical activity, exercise, aerobic fitness, training, sport, APOE4, Alzheimer's disease, AD and dementia. By cross-referencing, additional publications were identified. Selected studies required older

S. Tokgöz · J. A. H. R. Claassen ( $₫)$

Radboud University Medical Center, Nijmegen, The

Netherlands

e-mail: jurgen.claassen@radboudumc.nl

S. Tokgöz · J. A. H. R. Claassen

Department of Geriatric Medicine, Radboudumc

Alzheimer Center, Nijmegen, The Netherlands

J. A. H. R. Claassen

Donders Institute for Brain, Cognition and

Behaviour, Nijmegen, The Netherlands adults to take part in an exercise intervention or to make use of self-reported physical activity questionnaires. All included studies were written and published in English between 2000 and 2020. From these studies, we conclude that exercise is a non-pharmacological treatment option for high-risk APOE $\varepsilon 4$ carriers to ameliorate the $\mathrm{AD}$ pathological processes including reducing $A \beta$ load, protecting against hippocampal atrophy, improving cognitive function, stabilizing cholesterol levels and lowering pro-inflammatory signals. Variation in study design related to age, cognitive outcomes and the type of intervention explained the differences in study outcomes. However, exercise seems to be effective in delaying the onset of $\mathrm{AD}$ and may improve the quality of life of $\mathrm{AD}$ patients.

Keywords: Alzheimer's disease; APOE4 genotype; Exercise intervention; Mild cognitive impairment; Physical activity 


\section{Key Summary Points}

Why carry out this study?

Alzheimer's disease is a major cause of death and disability and constitutes a large economic burden.

ApoE- $\varepsilon 4$ is a strong genetic risk factor for Alzheimer's disease.

This review investigated whether this genetic risk could be modified by environmental factors, specifically physical activity or exercise.

\section{What was learned from the study?}

Several studies have examined interactions and associations between exercise and ApoE- $\varepsilon 4$ on mechanisms that contribute to the risk of Alzheimer's disease.

Exercise may mitigate the negative effects of ApoE- $\varepsilon 4$ on amyloid-beta 42 metabolism, neuroinflammation, neurotrophic factors, cerebral blood vessels and cognitive function, and thereby reduce the risk of Alzheimer's disease.

\section{DIGITAL FEATURES}

This article is published with digital features to facilitate understanding of the article. You can access the digital features on the article's associated Figshare page. To view digital features for this article go to https://doi.org/10.6084/m9. figshare.13322291.

\section{INTRODUCTION}

Alzheimer's Disease (AD) is a progressive neurodegenerative disease affecting cognitive function. This cognitive decline manifests as deficits including memory loss, communication

problems, agnosia, apraxia and executive function impairment [1]. AD is the most common form of dementia. Quality of life is impaired in patients with dementia due to the reduced ability of daily-life functioning. The best known molecular mechanisms behind $\mathrm{AD}$ are amyloid plaque deposition and hyperphosphorylated tau proteins forming neurofibrillary tangles in the brain. Neuronal connections within the brain are disrupted by these protein aggregates, leading to regional atrophy. The blood circulation system may have a protective role in preventing aggregation by clearance of these proteins. However, the clearance of protein aggregates is deficient in $\mathrm{AD}$ due to cellular, molecular and genetic imbalances.

$\mathrm{AD}$ can be divided into an early-onset (age $<60)$ and the more common late-onset form. Genetic, clinical and lifestyle-related risk factors play a role in the development of AD. Early-onset $\mathrm{AD}$ is mainly caused by genetic variations in the APP gene encoding amyloid- $\beta$ precursor protein, or PSEN1 and PSEN2 genes encoding presenilins I and II, respectively. These three genes have been found to play an important role in amyloid- $\beta$ (A $\beta$ ) production. Cleavages of APP via $\beta$-secretase and $\gamma$-secretase secrete $A \beta$ of several lengths, of which the most common forms are the 40- and 42-amino acid $\mathrm{A} \beta$ ( $\mathrm{A} \beta 40$ and $\mathrm{A} \beta 42$, respectively). The latter isoform has a more hydrophobic structure, making it more susceptible to deposition in the brain. Both PSEN1 and PSEN2 proteins constitute the catalytic part of the $\gamma$-secretase complex [2]. Mutations in PSEN affect the A $\beta 42 / 40$ ratio, resulting in elevated $A \beta 42$ [3].

The late-onset form of AD is also genetically determined, albeit to a lesser extent. Genomewide association studies have revealed the important role of the apolipoprotein E (APOE) gene encoding the ApoE protein on chromosome 19 in late-onset AD [4]. The ApoE protein is involved in the transport and metabolism of lipids, and it exists in three common isoforms: ApoE2, ApoE3 and ApoE4, encoded by APOE $\varepsilon 2$, $\varepsilon 3$ and $\varepsilon 4$, respectively. They vary at amino acid residues 112 or 158, which results in significant differences in their functioning [5]. The APOE $\varepsilon 2$ allele is protective against $\mathrm{AD}$, whereas the $\varepsilon 3$ allele has a neutral effect [6]. The risk of late- 
onset $\mathrm{AD}$ increases with the presence of one or two APOE $\varepsilon 4$ alleles [7]. Furthermore, the age of onset will decrease in a dose-dependent relation with the APOE $\varepsilon 4$ allele [8]. Besides the risk of $\mathrm{AD}$, APOE $\varepsilon 4$ homozygotes also demonstrate neuropathological characteristics of the disease such as increased A $\beta$ deposition [4]. Previous studies have reported $A \beta$ accumulation in an isoform-dependent fashion as ApoE4 > ApoE3 > ApoE2 $[9,10]$. Since APOE $\varepsilon 4$ carriers have lower cerebrospinal fluid (CSF) and plasma ApoE protein levels [10-12], the ApoE protein is suggested to be involved in preventing the accumulation of $A \beta$ plaques $[13,14]$. The ApoE4 protein is implicated in many other processes that may influence $\mathrm{AD}$, including lipid metabolism, tau phosphorylation, cholesterol homeostasis, mitochondrial function, neuroinflammation, vascular function and synaptic plasticity [14].

To date, pharmacological agents only provide symptomatic treatment by targeting, for example, the synaptic dysfunction, $\mathrm{A} \beta$ accumulation and phosphorylation signalling pathways [15], and the efficiency can be increased by combining therapeutics [16]. However, reversing a multimodal disease such as $\mathrm{AD}$ still remains a challenge. The risk of $\mathrm{AD}$ is also influenced by lifestyle factors such as blood pressure, smoking, physical activity and cholesterol [17]. Much research is focused on non-pharmacological approaches including exercise. Previous studies have found positive effects of exercise on cognition in $\mathrm{AD}[18,19]$. Burns et al. found cardiorespiratory fitness to be protective against brain atrophy in early $\mathrm{AD}$ patients [20]. Furthermore, aerobic exercise in early $\mathrm{AD}$ was associated with reduced hippocampal atrophy and improved memory performance [21]. It was suggested that lifestyle intervention in APOE $\varepsilon 4$ carriers may modify dementia risk, since the risk of dementia in these individuals was found to increase with adverse lifestyle factors such as physical inactivity [22]. Previous systematic reviews have focused on exercise and $\mathrm{AD}$, but the association with the APOE4 genotype has received limited attention. The objective of this review is to highlight the modulatory role of exercise on $\mathrm{AD}$ pathology in APOE $\varepsilon 4$ carriers. We will review the effect on several mechanisms contributing to $\mathrm{AD}$ including cognitive function, $\mathrm{A} \beta$ metabolism, lipid metabolism, neuroinflammation, neurotrophic factors and vascularization. We will discuss both human and animal studies. This article is based on previously conducted studies and does not contain any new studies with human participants or animals performed by either of the authors.

\section{PHYSICAL ACTIVITY IN APOE $\varepsilon 4$ CARRIERS}

\section{Cognitive Function}

Cognitive decline in $\mathrm{AD}$ dementia affects most daily life activities. Thus, a growing need arises to ameliorate progressive cognitive symptoms. There is some evidence supporting the effectiveness of exercise as therapy (Table 1). Jensen et al. found that AD patients carrying the APOE $\varepsilon 4$ gene and who were engaged in an exercise intervention showed an improvement of neuropsychiatric symptoms and stabilized cognition as assessed by the symbol digit modalities test (SDMT) in comparison to non-carriers and controls [23]. The exercise intervention consisted of supervised aerobic exercise three times a week for 16 weeks. Results showed that these carriers improved the physical, cognitive and neuropsychiatric outcomes compared to noncarriers. Similarly, APOE $\varepsilon 4$ mice engaged in aerobic exercise demonstrated improved cognition and hippocampal function [24]. Cognition in these transgenic mice was tested by object and place recognition tests. A study by Etnier et al. supported the protective effect of aerobic exercise on cognition in cognitively normal older women carrying the APOE 4 \&4 allele [25], based on different cognitive tests including an auditory verbal learning test, the complex figure test and the Wisconsin Card Sorting Test. Lautenschlager et al. studied the effect of a 24-week home-based physical activity intervention on cognitive function in adults with subjective memory impairment [26]. Physical activity was assessed with a survey in combination with data obtained from a pedometer to avoid bias. This study demonstrated that 


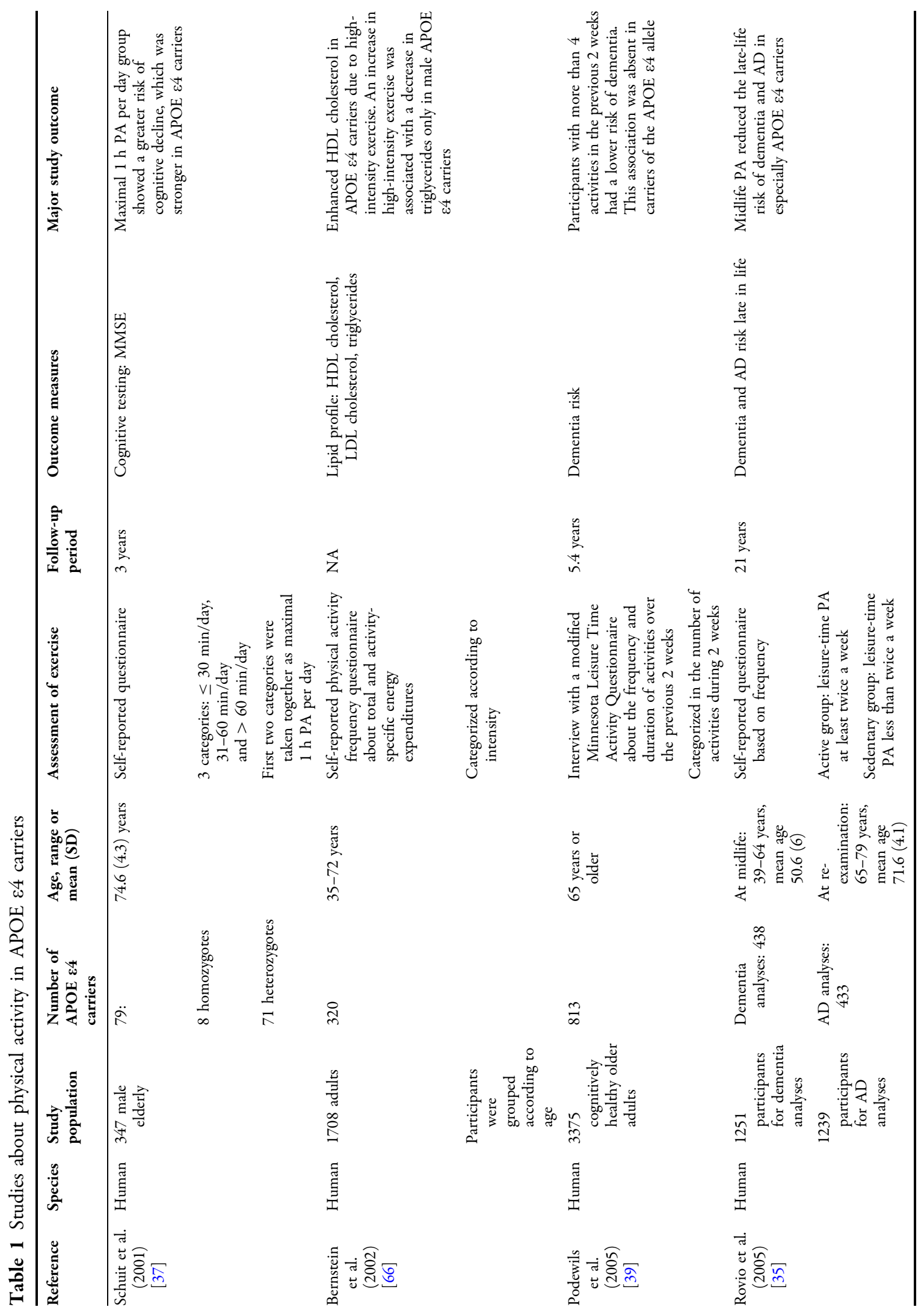




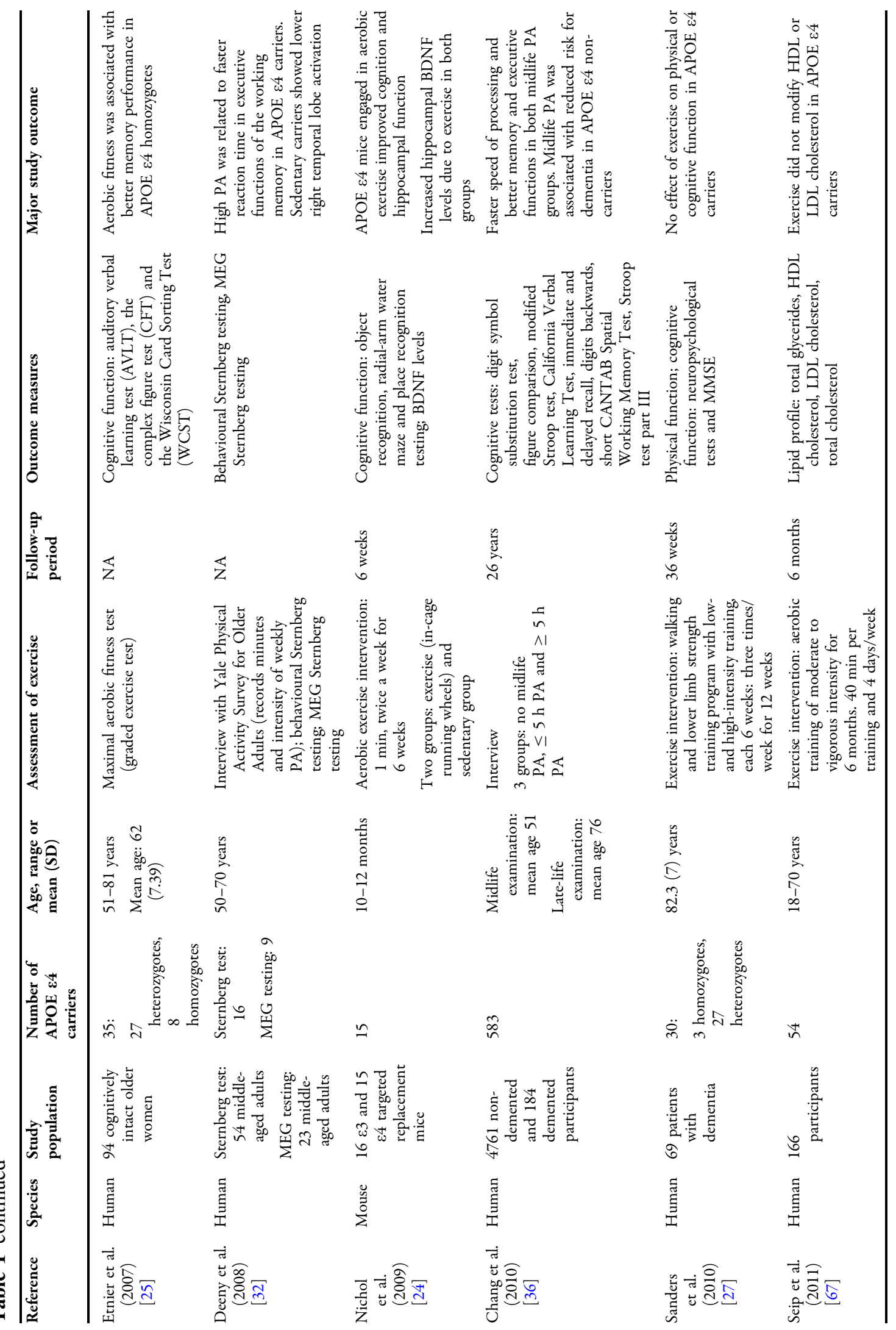




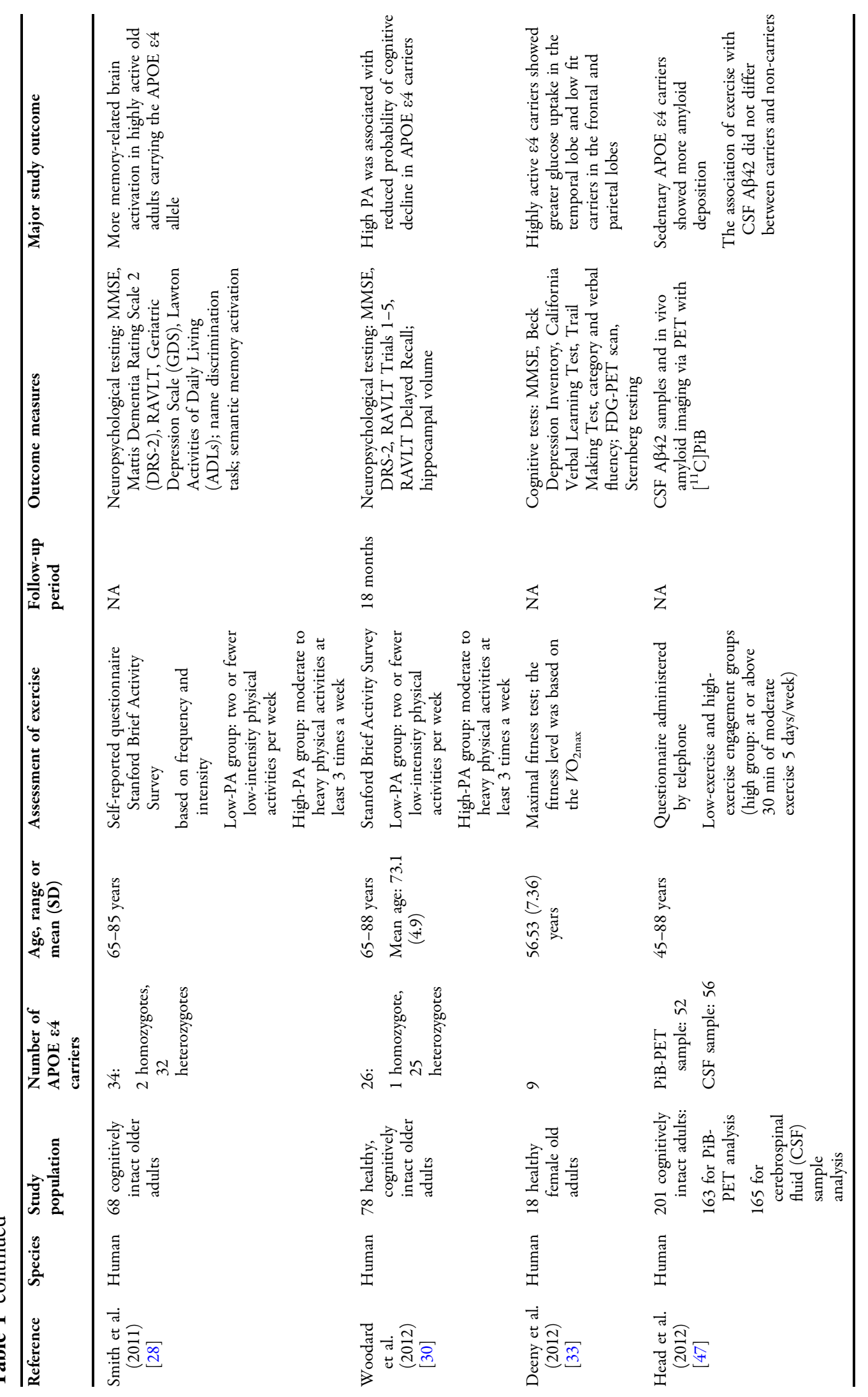




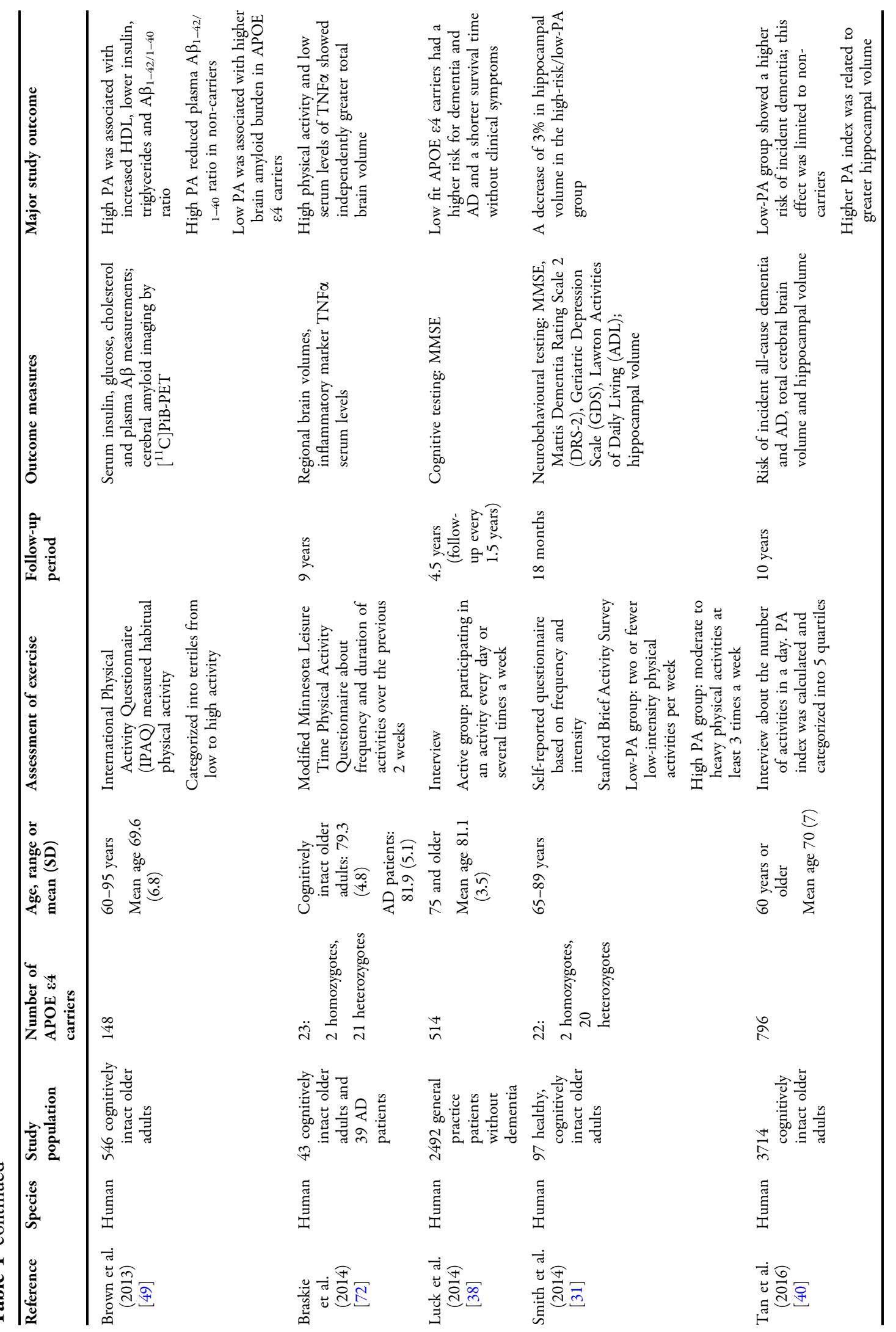




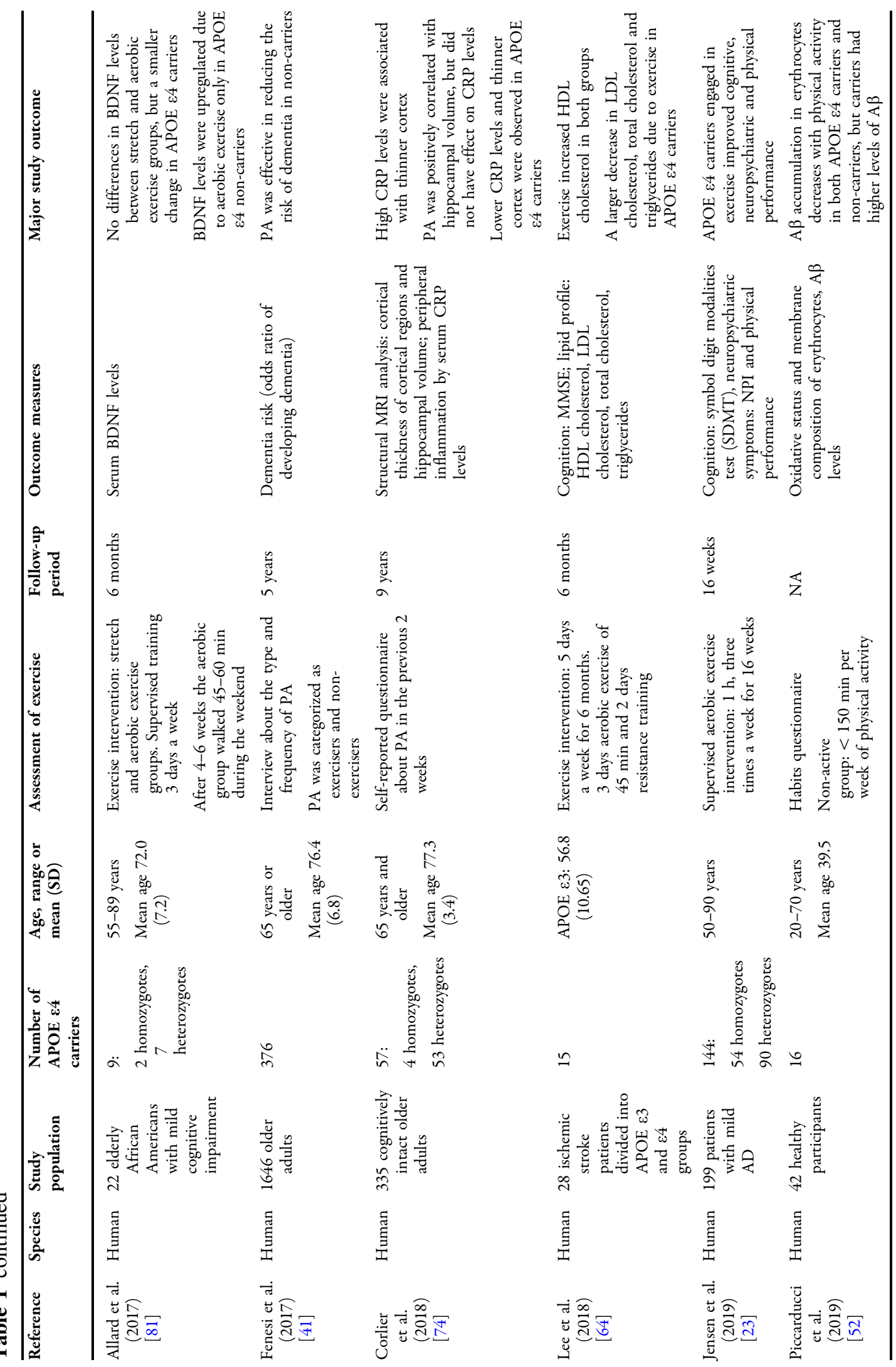




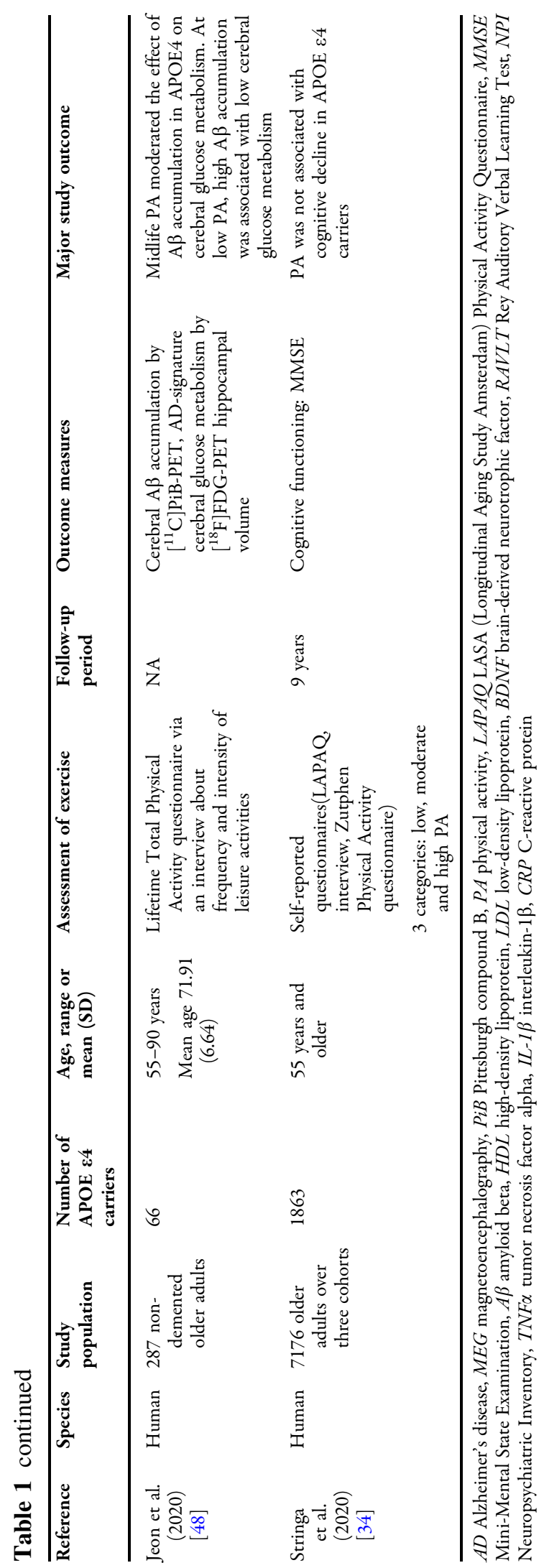


exercise improved cognitive function in adults aged 50 years or older, of whom $30 \%$ were carriers of the APOE $\varepsilon 4$ allele. Additional analysis revealed that APOE $\varepsilon 4$ non-carriers in the intervention group scored better on the Alzheimer's Disease Assessment Scale-Cognitive Subscale (ADAS-Cog) test compared to carriers and controls, as expected. On the contrary, a recent study by Sanders et al. showed that a 24-week aerobic exercise program did not modify cognitive function in APOE $\varepsilon 4$ carriers with dementia [27]. Methods used to quantify the physical activity in this study were highly variable among patients with dementia. Therefore, the association between physical activity and cognitive function in APOE $\varepsilon 4$ carriers could be absent.

The majority of studies assessed the physical activity by self-reported questionnaires (Table 1). Smith et al. found that high physical activity promoted cortical semantic processing activity on the name discrimination task among APOE $\varepsilon 4$ carriers who were older cognitively intact adults [28]. Greater cortical semantic activation may protect older adults against future cognitive decline [29]. A follow-up study revealed that reduced predicted probability of cognitive decline in APOE $\varepsilon 4$ carriers was associated with high physical activity [30]. Furthermore, APOE $\varepsilon 4$ carriers with low physical activity in daily life had decreased hippocampal volume after 18 months, whereas the high physical activity group remained stable over time [31]. Physical activity could have a protective effect against hippocampal atrophy in APOE $\varepsilon 4$ carriers, which in turn may reduce cognitive decline. A magnetoencephalography (MEG) study of participants aged between 50 and 70 found that highly active APOE $\varepsilon 4$ carriers had a faster processing speed in working memory executive function [32]. In addition, carriers with low levels of physically activity showed decreased right temporal lobe activation. Another study on working memory revealed higher glucose uptake in core regions involved in working memory such as frontal, parietal, temporal and cerebellar regions in highly active $\varepsilon 4$ carriers with a mean age of $63.67 \pm 6.37$ years [33]. However, a recent multi-cohort study by Stringa et al., consisting of older adults with a mean age of 67.8 years at baseline, indicated that physical activity did not moderate cognitive decline in APOE $\varepsilon 4$ carriers [34]. For each cohort, a different self-reported questionnaire was used to assess the physical activity, which was classified into three categories including inactive, light and moderate-high activity based on walking, cycling, diverse sports and hobbies. Cognitive function was assessed with the Mini-Mental State Examination (MMSE).

\section{AD Dementia Risk}

Midlife or late-life exercise influences dementia risk. Some studies examined the effect of midlife exercise on dementia risk in adults aged younger than 65 . APOE $\varepsilon 4$ carriers showed a significant inverse association between midlife physical activity and dementia risk compared to non-carriers [35], while in the AGES-Reykjavik study, the association between midlife physical activity and late-life cognition was strongest in non-carriers [36]. The combination of physical activity and the presence of an APOE $\varepsilon 4$ allele may modify the risk of developing $\mathrm{AD}$ dementia later in life, but more replication is required. On the contrary, late-life physical activity seems to be effective in reducing dementia risk. The beneficial effect of late-life physical activity on the risk of cognitive decline was more pronounced in APOE $\varepsilon 4$ carriers [37]. In addition, physical activity in late life may be beneficial in APOE $\varepsilon 4$ carriers by reducing the risk of $\mathrm{AD}$ dementia and delaying its onset [38].

One of the studies that did not find any significant interaction between physical activity and the APOE4 genotype is the Cardiovascular Health Cognition Study, wherein a significant association between physical activity and dementia was observed in non-carriers, but not in APOE $\varepsilon 4$ carriers, after a follow-up period of approximately 5 years [39]. However, only 28 APOE \&4 carriers showed cognitive decline in this period, making the interaction with physical activity subject to variability. In addition, the Framingham study showed increased risk of dementia in sedentary non-carriers aged 60 years and older, suggesting an inverse 
association between physical activity and dementia risk [40]. A study of 1646 older adults followed over a 5-year period reported that physical exercise was effective in preventing dementia in non-carriers [41]. No significant differences were observed between active and non-active APOE $\varepsilon 4$ carriers. Several findings have been reported about the association between midlife or late-life exercise and $\mathrm{AD}$ dementia risk in APOE $\& 4$ carriers. Exercise seems to modify $\mathrm{AD}$ dementia risk, but more replication is required to infer whether this is characteristic of APOE $\varepsilon 4$ carriers.

\section{A $\beta$ Metabolism}

Aggregation of $A \beta$ peptides in the brain is one of the pathological hallmarks of AD. The most abundant forms are $A \beta 40$ and $A \beta 42$, with the latter known to be deposited more easily because of its hydrophobic and fibrillogenic composition [42]. In the healthy central nervous system, $A \beta$ is rapidly produced and cleared, with a production rate of $7.6 \%$ per hour and a clearance rate of $8.3 \%$ per hour [43]. Due to molecular, cellular and genetic imbalances, the clearance of $A \beta$ via the blood circulation system is deficient in late-onset AD. Mawuenyega et al. found impaired clearance of both $A \beta 40$ and $A \beta 42$ in the central nervous system of late-onset $\mathrm{AD}$ patients compared with cognitively healthy controls, whereas the production rates did not differ [44]. The effectiveness of $\mathrm{A} \beta$ clearance depends on APOE isoforms, decreasing from APOE2 to APOE3 to APOE4 [45]. This defect in clearance could lead to $A \beta$ plaques that aggregate in the cortex. Transgenic AD mice showed reduced $A \beta$ plaques and amyloid angiopathy if they performed aerobic exercise in their enriched housing [46]. This raises the question of whether exercise is associated with cerebral $A \beta$ deposition in APOE $\varepsilon 4$ carriers. Head et al. suggested that APOE $\varepsilon 4$ carriers with low exercise levels might have increased risk for cerebral $A \beta$ deposition [47]. A recent study by Jeon et al. investigated whether APOE $\varepsilon 4$ status combined with high midlife physical activity could modify $\mathrm{A} \beta$ retention [48]. APOE $\varepsilon 4$ carriers with a mean age of 72 years in a low physical activity state had higher $A \beta$ accumulation, and this was absent in highly active carriers. Furthermore, a study of 546 cognitively healthy elderly individuals with an average age of $69.6 \pm 6.8$ years revealed decreased cerebral amyloid load in physically active APOE $\varepsilon 4$ carriers, whereas high physical activity was associated with a reduced plasma $A \beta 42 / 40$ ratio only in non-carriers [49].

A difference between $A \beta$ in the brain and the periphery related to the ApoE4 protein seems plausible. The APOE $\varepsilon 4$ allele alters the permeability of the blood-brain barrier, which may result in increased levels of $A \beta$ in the peripheral system of carriers compared to non-carriers [50]. This could be one explanation why reduced plasma $A \beta$ levels were observed only in highly physically active non-carriers. $A \beta$ fibrils in the periphery have an increased affinity for binding erythrocytes that can take up these fibrils, resulting in oxidative stress [51]. Piccarducci et al. confirmed that APOE $\varepsilon 4$ carriers have higher levels of $A \beta$ in erythrocytes than noncarriers [52]. The $A \beta$ levels in erythrocytes decreased with physical activity in both carriers and non-carriers, but the decrease in APOE $\varepsilon 4$ in non-carriers was significantly greater than that in carriers. Although the reduction in $A \beta$ accumulation in erythrocytes related to physical activity seems to be independent of the APOE4 genotype, physical activity may have a beneficial role in relieving oxidative stress in APOE $\varepsilon 4$ carriers.

Neprilysin (NEP) and insulin-degrading enzyme (IDE) are important enzymes in maintaining the $A \beta$ levels in the brain. NEP, a zinc metalloendopeptidase, is involved in the degradation of $A \beta$ in monomeric and oligomeric forms in the brain [53]. IDE, also a zinc metalloendopeptidase, has the ability to degrade extracellular $A \beta$ in the brain and to clear cytoplasmic products of APP [54]. Studies have shown that these enzymes are downregulated due to age-dependent genetic mutations which could lead to $\mathrm{AD}$ by disrupting cerebral A $\beta$ clearance (Fig. 1) [54-56]. Moore et al. used $\mathrm{AD}$ transgenic mice with elevated $\mathrm{A} \beta$ levels to show the effect of exercise on $A \beta$ metabolism [57]. They investigated reduced levels of both soluble $A \beta 40$ and $A \beta 42$ in the cortex and hippocampus by exercise in a dose-dependent 


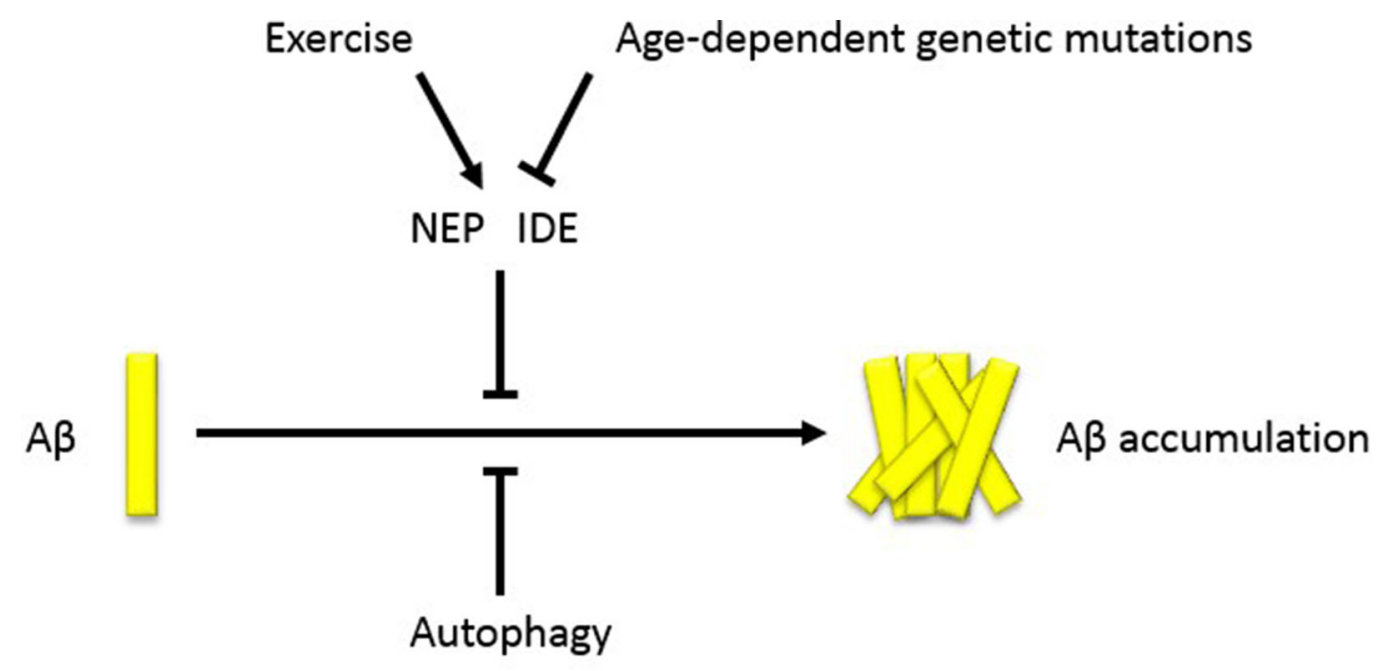

Fig. 1 The influence of exercise on $A \beta$ accumulation. In the healthy brain, $A \beta$ levels are maintained by autophagy and $A \beta$-degrading enzymes NEP and IDE. Age-dependent genetic mutations may affect NEP and IDE, leading to $A \beta$

manner. Exercise may be beneficial for APOE $\varepsilon 4$ carriers, since the ApoE4 protein can enhance $A \beta 40$ and $A \beta 42$ aggregation compared to the other two isoforms [58]. NEP and IDE expression were also increased in the exercise groups in a dose-dependent fashion, providing further evidence that exercise may upregulate these $A \beta$ degradation enzymes, leading to $A \beta$ clearance (Fig. 1).

\section{Lipid Metabolism}

Lipids are crucial molecules in the human body. The central nervous system has the second highest lipid content after the adipose tissue [59]. Signal transduction in the brain depends on lipids as well, since axons are surrounded by a myelin sheath consisting of lipids. In addition, the ApoE protein is involved in lipid transport by regulating lipoprotein concentrations. ApoE proteins are attached to the surface of lipoproteins filled with lipids, enabling the binding to receptors on tissue or cells. In the central nervous system, ApoE released by astrocytes is needed to transport cholesterol inside lipoproteins to neuronal cells $[6,52]$. This process starts with the binding of ApoE to highdensity lipoprotein (HDL) filled with accumulation. Exercise engagement may promote $\mathrm{A} \beta$ clearance indirectly by upregulating the A $\beta$-degrading enzymes. $A \beta$ amyloid- $\beta, N E P$ neprilysin, IDE insulindegrading enzyme

cholesterol. ApoE has high affinity for binding to the low-density lipoprotein (LDL) receptor family at cell surfaces mediating endocytosis, where HDL is degraded and cholesterol is released [60]. Cholesterol is crucial for axonal growth and formation and remodelling of synapses, which are important for learning, memory formation and neuronal repair [6]. Previous studies found lower ApoE levels in the serum, brain and cerebrospinal fluid in both APOE $\varepsilon 4$-carrying AD patients and cognitively normal persons [61]. A reduction in ApoE can affect cholesterol transport in the brain. In AD, brain cholesterol levels are commonly reduced in hippocampal neurons and cortical areas. Furthermore, cholesterol transport to hippocampal neurons occurs in an isoform-dependent manner, where the ApoE3 protein is more efficient than ApoE4 [62]. Animal studies have shown consistent results of decreased brain cholesterol in homozygous $\varepsilon 4$ mice [63].

Cholesterol can be transported by either HDL or LDL in serum; the latter enhances the risk of atherosclerosis, leading to cardiovascular disease, stroke and dementia [64]. It has been widely demonstrated that APOE $\varepsilon 4$ carriers show lower HDL and higher LDL cholesterol serum levels [52, 65]. ApoE4-knock-in mice also 
showed increased serum LDL cholesterol [63]. Evidence was found that physical activity may modify the altered lipid profile; for instance, physical activity in older adults was positively associated with HDL cholesterol [49]. Bernstein et al. (2002) found that high levels of physical activity may reduce the atherosclerosis risk of the APOE4 genotype on the lipid profile [66]. Furthermore, highly active APOE $\varepsilon 4$ carriers consisting of men and women between the ages of 35 and 74 years showed enhanced HDL cholesterol. Due to the large age range, the groups were divided into $<55$ and $50+$ years, where the association between high physical activity and the APOE4 genotype was more pronounced among the $50+$ group. Lee et al. (2018) suggested that exercise training may decrease LDL cholesterol levels and total cholesterol in APOE $\varepsilon 4$-carrying ischemic stroke patients [64]. In particular, in relatively young participants, no change in HDL or LDL cholesterol level was observed after physical training in APOE $\varepsilon 4$ carriers [67]. These results indicate that age is an important factor in modifying cholesterol levels in APOE $\& 4$ carriers by exercise. High physical activity reduces the high-risk LDL cholesterol in older APOE \&4 carriers compared to their younger counterparts. Taken together, these observations build a strong case supporting the association between exercise and lipid profiles of APOE $\varepsilon 4$ carriers.

\section{Neuroinflammation}

Neuroinflammation is involved in the neurodegenerative process in $\mathrm{AD}$. Microglia and astrocytes are the central innate immune cells of the central nervous system. Microglia can be activated by the presence of $A \beta$ to induce phagocytosis of $A \beta$ plaques. However, activated microglia are not able to clear $A \beta$ aggregation, leading to inflammation and thereby recruitment of more microglia, which can lead to cytotoxicity [68]. Upon activation, microglia release cytokines to regulate neuroinflammation, but these pro-inflammatory cytokines can induce damage to surrounding neurons and even cause neurodegeneration as occurs in later stages of AD. ApoE is involved in microglia suppression, which has a protective effect on neuroinflammation by inducing anti-inflammatory cytokines. ApoE-deficient mice showed enhanced levels of pro-inflammatory cytokines including tumor necrosis factor alpha $(\mathrm{TNF} \alpha)$, interleukin-1 $\beta$ (IL-1 $\beta$ ) and interleukin 6 (IL-6) mRNA by stimulation with lipopolysaccharide [69]. These pro-inflammatory cytokines were significantly increased, especially in APOE4 mice [70]. Administration of an ApoE-mimetic peptide derived from the receptor-binding region of the ApoE holoprotein counteracts this effect, showing its protective role in neuroinflammation. The innate immune response seems to be influenced by specific APOE isoforms. Soto et al. demonstrated evidence to support ApoE as a key player in neuroinflammation [71]. Aged mice engaged in exercise showed a reduction in microglia activation and improved neurovascular functioning and behaviour, whereas ApoE-deficient mice did not benefit from the intervention, suggesting the important role of ApoE in neurovascular functioning. Another animal study revealed that exercise in an enriched housing environment was effective in downregulating pro-inflammatory genes and upregulating anti-inflammatory genes in transgenic AD mice, which may reduce $\mathrm{A} \beta$ deposition in the brain [46]. Braskie et al. studied the relation between physical activity, inflammation and risk of $\mathrm{AD}$ in cognitively healthy older adults and AD patients [72]. They did not find an association between physical activity and $\mathrm{TNF} \alpha$, but lower $\mathrm{TNF} \alpha$ and high physical activity levels were both independently associated with reduced regional brain atrophy. On the contrary, the animal study by Nichol et al. showed that exercise in aged AD mice reduced pro-inflammatory cytokines such as TNF $\alpha$ and IL-1 $\beta$, thereby activating an adaptive response around $A \beta$ plaques leading to decreased $A \beta$ [73].

During inflammation, C-reactive protein (CRP) is mainly upregulated in serum. At the same time, pro-inflammatory cytokines are released. The study by Corlier et al. (2018) 
followed cognitively healthy older adults for 9 years [74]. Over time, CRP levels were enhanced, which was associated with greater cortical thinning. Physical activity was not related to CRP levels, which could be due to bias in the self-reports. The APOE4 genotype showed lower CRP levels and thinner cortex, which is contradictory in terms of inflammation. Therefore, Corlier et al. suggested that other mechanisms could be responsible for the enhanced $A D$ risk in APOE4 carriers. The low CRP in APOE $\varepsilon 4$ carriers was also supported by a previous study [75]. It was suggested that the low CRP levels in $\varepsilon 4$ carriers are not associated with neuroinflammation, due to contradictory findings of increased inflammation in these carriers and low CRP levels. It remains unclear, but a possible explanation may be the production of cholesterol by the mevalonate pathway of the liver, because this pathway is known to be downregulated in APOE $\varepsilon 4$ carriers, leading to low levels of CRP [75].

\section{Neurotrophic Factors}

We previously mentioned that exercise can reduce pro-inflammatory cytokines. Exercise is also indirectly involved in growth factor stimulation. Insulin-like growth factor 1 (IGF-1) and brain-derived neurotrophic factor (BDNF) are growth factors involved in hippocampal function, synaptic functioning and learning. Exercise may upregulate both growth factors in the brain and periphery directly by increasing the concentrations or indirectly by reducing proinflammatory cytokines, which could alter IGF1 and BDNF signalling in neurons [76]. IGF-1 has a protective role in $\mathrm{AD}$ because of its ability to decrease $A \beta$ deposition. This growth factor is involved in upregulating the transport of $A \beta$ carrier proteins to the brain to increase the clearance of $A \beta$ plaques [77]. In this way, cognitive functioning is improved. A recent study by Galle et al. found low IGF-1 levels in homozygous APOE $\varepsilon 4$ carriers showing increased risk of dementia [77]. Besides the role of IGF-1 in $\mathrm{AD}, \mathrm{BDNF}$ is important in maintaining the memory function. The APOE $\varepsilon 4$ allele reduces BDNF expression, which may induce synaptic loss in the hippocampus, leading to cognitive deficits [78]. Aerobic exercise was found to compensate the hippocampal volume loss in late adulthood that was associated with increased plasma levels of BDNF [79]. In addition, plasma BDNF levels were increased in $\mathrm{AD}$ patients due to aerobic exercise [80]. Conversely, BDNF levels were upregulated due to aerobic exercise only in APOE $\varepsilon 4$ non-carriers and not in carriers [81]. However, this study was restricted to one ethnic group with a higher risk of AD. An animal model showed increased hippocampal BDNF levels upon exercise in both APOE $\varepsilon 4$ and APOE $\varepsilon 3$ transgenic mice [24]. Studies assessing the effects of exercise on neurotrophic factors in APOE e4 carriers are sparse, but the available evidence may support a relation between the two, suggesting more replication is needed.

\section{Vascularization}

Vascular risk factors including hypertension, hypercholesterolemia, atrial fibrillation and smoking can affect the incidence and progression of AD [82]. For example, high systolic blood pressure in APOE $\varepsilon 4$ carriers may lead to cognitive decline $[83,84]$. Caselli et al. noted that any of the cerebrovascular risk factors including hypercholesterolemia, hypertension, smoking and diabetes mellitus may potentiate age-dependent memory deficits in APOE $\varepsilon 4$ homozygotes [85]. These vascular risk factors induce vascular oxidative stress by downregulation of vascular nitric oxide (NO) and endothelial NO synthase (eNOS) pathways, which can impair vascular reactivity in the form of hypercontractility. Cerebral blood flow (CBF) will decrease due to impaired vasodilation, which mediates oxidative stress and promotes neuronal degeneration. In addition, $A \beta$ plays a role in this process by inhibiting eNOS activity. This is supported by the finding that hypertensive mice showed increased permeability of the blood-brain barrier in the cortex and 
hippocampus and $\mathrm{A} \beta$ deposition [86]. A human study demonstrated that hypertensive APOE $\varepsilon 4$ carriers aged $49-89$ years had greater cortical amyloid burden as quantified by PET imaging compared to hypertensive non-carriers, normotensive carriers and non-carriers [87]. Zhang et al. found decreased eNOS activity, increased $\mathrm{A} \beta$ in the hippocampus and cortex, and decreased cognition in hypertensive mice [88]. Engagement in exercise led to improved eNOS levels, cognition and $\mathrm{AD}$ pathology. In addition, long-term exercise increased IGF-1 levels in these hypertensive mice, which is important in attenuating $A \beta$ clearance.

Reduced CBF is another hallmark of AD. Older adults carrying the APOE $\varepsilon 4$ allele showed lower CBF than non-carriers, along with reduced memory [89]. Adult APOE4-mice had reduced $\mathrm{CBF}$ in regions susceptible to $\mathrm{AD}$ pathology compared to wild-type mice and younger mice with the APOE $\varepsilon 4$ allele, suggesting an age-dependent interaction [90]. Since APOE $\varepsilon 4$ carriers have lower levels of the ApoE protein, a complete knock-out of the ApoE protein resulted in lower CBF compared to wildtype mice already at a young age, demonstrating the importance of the ApoE protein. It has been shown that exercise is effective in increasing CBF. Aged mice showed increased CBF in the hippocampus with walking [91]. Burdette et al. reported increased hippocampal CBF with a 16-week exercise program in older adults at risk for cognitive decline and with subjective cognitive impairment [92]. Furthermore, greater hippocampal connectivity was observed in the exercise group. Conversely, a 16-week aerobic program was not sufficient to increase $\mathrm{CBF}$ in $\mathrm{AD}$ patients [93].

Vascular endothelial-derived growth factor (VEGF) is another important factor involved in vascularization. VEGF is lower in AD [94], and especially in APOE $\varepsilon 4$ carriers, compared to the other isoforms, which may lead to vascular impairment. By increasing the VEGF levels using a viral vector, the AD-related pathology in APOE \&4-carrying mice was reversed [95]. Exercise may increase the VEGF plasma levels to improve vascularization [76]. Increased VEGF expression was found to induce angiogenesis in aged mice through exercise engagement [96]. Studies about the association between VEGF levels in APOE $\varepsilon 4$ carriers and exercise are sparse.

\section{DISCUSSION}

This review focused on both human and animal studies that highlighted the role of exercise in APOE $\varepsilon 4$ carriers with respect to the risk of AD dementia for the following domains: cognitive function, $A \beta$ metabolism, lipid metabolism, neuroinflammation and vascularization. Exercise may modify the association between the APOE $\varepsilon 4$ allele and AD-related pathology (Table 1).

The APOE $\varepsilon 4$ allele increases the risk of AD. Carriers of this allele were shown to have lower levels of the ApoE protein, which is needed in many processes for proper functioning. Due to this lack of the ApoE protein in APOE $\varepsilon 4$ carriers, cholesterol transport is affected, which may lead to higher LDL and lower HDL cholesterol transport and increased AD pathology. Through engagement in exercise, the risk of atherosclerosis may be lowered. Together with deficits in cholesterol transport, neuroinflammation may be induced by lack of ApoE. Since ApoE is involved in suppression of microglia to reduce pro-inflammatory cytokines, lower levels of ApoE could reverse this process. Upregulation of pro-inflammatory cytokines, as shown in APOE \&4 carriers, may downregulate IGF-1 and thereby increase $A \beta$ pathology. In addition, BDNF levels may inhibit the induction of hippocampal volume loss. Lower levels of both IGF-1 and BDNF were observed in APOE $\varepsilon 4$ carriers. Exercise is known to be effective in enhancing the levels of these growth factors, but the exact effect in APOE $\varepsilon 4$ carriers remains unknown. However, our findings suggest that exercise may play a role in reducing pro-inflammatory cytokines and upregulating IGF-1 and BDNF in APOE $\varepsilon 4$ carriers, because of the lower levels of the ApoE protein. 
The majority of studies showed that $A \beta$ metabolism could be improved by exercise. Exercise was found to reduce the cerebral amyloid load in APOE $\varepsilon 4$ carriers. We observed that carriers with low physical activity levels had increased risk of $A \beta$ deposition. In contrast, enzymes involved in the clearance of $A \beta$ were upregulated by exercise. Improvement of $A \beta$ metabolism may reduce cognitive deficits in AD. Low IGF-1 levels in APOE $\varepsilon 4$ carriers were found to play a role in impaired clearance of $A \beta$ deposition. Since exercise may ameliorate $A \beta$ metabolism in APOE $\varepsilon 4$ carriers and can increase IGF-1 levels in general, we suggest a relation of exercise with IGF-1 levels on the APOE $\varepsilon 4$ allele.

In terms of cognitive function, exercise seems to be effective in reducing cognitive decline in APOE $\varepsilon 4$ carriers. Exercise interventions improved cognition and hippocampal function in both human and animal studies [23-25]. Cognitive function was assessed mainly by neuropsychological tests. For example, Jensen et al. used the SDMT neuropsychological test, which is sensitive to very early changes in determining dysfunctional aspects of executive function in $\mathrm{AD}$ [23]. Intervention studies with contradictory findings related to cognitive function in APOE \&4 carriers were limited by participant age or variability in cognitive tests. A portion of the studies assessed physical activity by survey, increasing the subjectivity of these outcomes. Most of the studies found positive associations between cognition in the APOE $\varepsilon 4$ genotype and physical activity. High physical activity may induce increased semantic processing activity, protection against hippocampal atrophy and faster speed of processing of the working memory. Physical activity might delay the onset of $\mathrm{AD}$ by acting on memory processes in the hippocampus of APOE $\varepsilon 4$ carriers.

The findings as to whether physical activity can ameliorate cognitive decline in APOE $\varepsilon 4$ carriers were heterogeneous. Multiple factors were shown to play a key role, including the type of cognitive test, the type of exercise, the use of exercise intervention versus self-reported questionnaires, the follow-up time, the age of participants and the course of dementia. We noted that most of the studies with contradictory results used less sensitive outcome variables, such as clinical diagnosis of dementia or MMSE scores, and these kinds of tests are not sensitive to preclinical cognitive ageing [32]. Furthermore, the type of exercise intervention is crucial, because of the differences between aerobic and anaerobic exercise. Aerobic exercise was proven to be more effective in AD pathology by reducing amyloid angiopathy in transgenic mice [46]. Exercise interventions also avoid the risk of bias, which is more prominent in self-reported assessment of physical activity. Participant age and the course of dementia are crucial factors in determining the outcomes, because dementia occurs mostly in the elderly and progresses with age: the older the participant, the greater the neural pathology accumulation and the greater the further decline in dementia. Some studies showed differences between midlife and late-life exercise, suggesting that age plays a crucial role. There are still questions as to whether a threshold related to age exists in the protective effect of exercise on neural pathology accumulation in APOE $\varepsilon 4$ carriers [41]. However, since the APOE $\varepsilon 4$ allele causes deleterious effects in neural protection and repair mechanisms, these carriers may be more influenced by lifestyle-related modifications [35].

\section{CONCLUSION}

Exercise could be a potential non-pharmacological therapeutic or prevention option for reducing the risk of $\mathrm{AD}$ in $\mathrm{APOE} \varepsilon 4$ carriers (Fig. 2). By preventing or slowing neurodegeneration, exercise could increase the quality of life of $\mathrm{AD}$ patients. In the future, further research targeting midlife exercise will expand our knowledge about early prevention and therapeutic opportunities to delay the onset of $\mathrm{AD}$ in $\mathrm{APOE} \varepsilon 4$ carriers. 

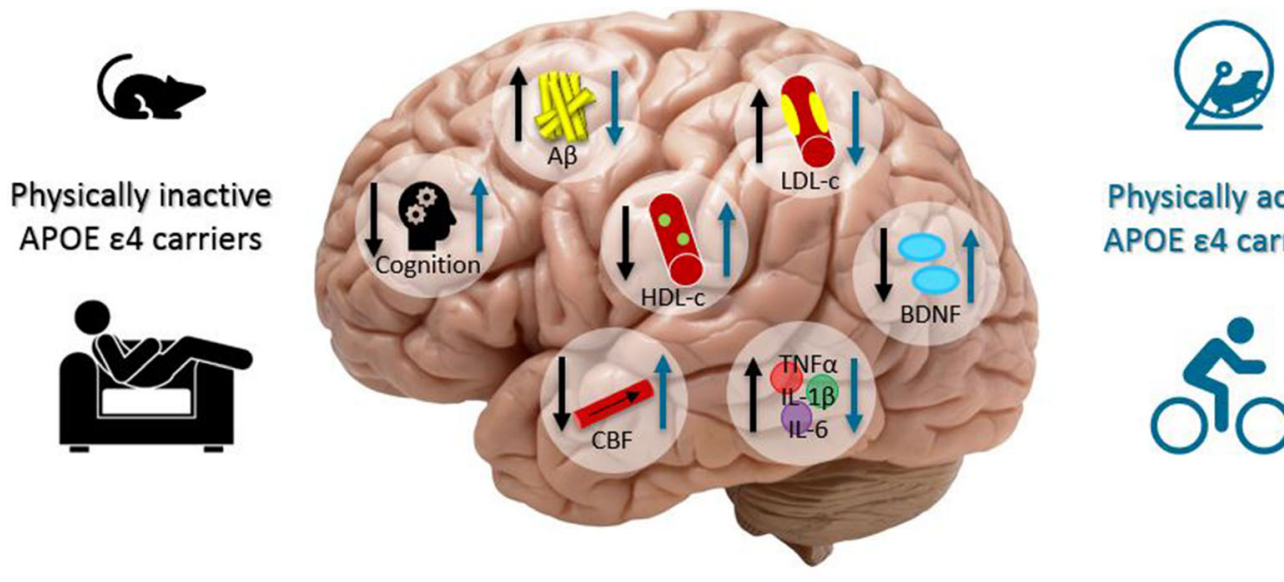

Physically active

APOE $\varepsilon 4$ carriers

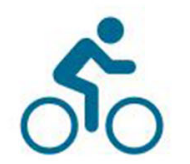

Fig. 2 Graphical summary of the results. Physically inactive APOE $\varepsilon 4$ carriers may have lower cognitive functioning, $\mathrm{CBF}, \mathrm{HDL}$ cholesterol, BDNF and higher $\mathrm{A} \beta$ accumulation, LDL cholesterol and neuroinflammation factors such as TNF- $\alpha$, IL- $1 \beta$ and IL- 6 compared to physically active APOE $\varepsilon 4$ carriers. Physical activity may be involved in the reduction of $A \beta$ accumulation, LDL cholesterol, neuroinflammation factors such as TNF- $\alpha$,
IL- $1 \beta$ and IL- 6 and in the increase of cognitive functioning, HDL cholesterol, CBF and BDNF in APOE $\varepsilon 4$ carriers. $A \beta$ amyloid- $\beta, H D L-c$ high density lipoprotein cholesterol, $L D L-c$ low density lipoprotein cholesterol, $C B F$ cerebral blood flow, $B D N F$ brain-derived neurotrophic factor, $T N F \alpha$ tumor necrose factor $\alpha, I L-1 \beta$ interleukin-1 $\beta, I L-6$ interleukin-6

human participants or animals performed by any of the authors.

Data Availability. Data sharing is not applicable to this article as no datasets were generated or analyzed during the current study.

Open Access. This article is licensed under a Creative Commons Attribution-NonCommercial 4.0 International License, which permits any non-commercial use, sharing, adaptation, distribution and reproduction in any medium or format, as long as you give appropriate credit to the original author(s) and the source, provide a link to the Creative Commons licence, and indicate if changes were made. The images or other third party material in this article are included in the article's Creative Commons licence, unless indicated otherwise in a credit line to the material. If material is not included in the article's Creative Commons licence and your intended use is not permitted by statutory regulation or exceeds the permitted use, you will need to obtain permission directly from the copyright holder. To view a copy of this licence, visit http://creativecommons.org/licenses/by$\mathrm{nc} / 4.0 /$. 


\section{REFERENCES}

1. Duong S, Patel T, Chang F. Dementia: what pharmacists need to know. Can Pharm J (Ott). 2017;150(2):118-29.

2. Lanoiselée H-M, Nicolas G, Wallon D, Rovelet-Lecrux A, Lacour M, Rousseau S, et al. APP, PSEN1, and PSEN2 mutations in early-onset Alzheimer disease: A GENETIC screening study of familial and sporadic cases. PLoS Med. 2017;14(3):e1002270-e.

3. Kabir MT, Uddin MS, Setu JR, Ashraf GM, BinJumah MN, Abdel-Daim MM. Exploring the role of PSEN mutations in the pathogenesis of Alzheimer's disease. Neurotox Res. 2020;38(4):833-49.

4. Naj AC, Schellenberg GD, Alzheimer's Disease Genetics C. Genomic variants, genes, and pathways of Alzheimer's disease: An overview. Am J Med Genet B Neuropsychiatr Genet. 2017;174(1):5-26.

5. Mamun AA, Uddin MS, Bin Bashar MF, Zaman S, Begum Y, Bulbul IJ, et al. Molecular insight into the therapeutic promise of targeting APOE4 for Alzheimer's disease. Oxid Med Cell Longev. 2020;2020:5086250.

6. Liu CC, Liu CC, Kanekiyo T, Xu H, Bu G. Apolipoprotein E and Alzheimer disease: risk, mechanisms and therapy. Nat Rev Neurol. 2013;9(2):106-18.

7. Corder EH, Saunders AM, Risch NJ, Strittmatter WJ, Schmechel DE, Gaskell PC Jr, et al. Protective effect of apolipoprotein E type 2 allele for late onset Alzheimer disease. Nat Genet. 1994;7(2):180-4.

8. Corder EH, Saunders AM, Strittmatter WJ, Schmechel DE, Gaskell PC, Small GW, et al. Gene dose of apolipoprotein $\mathrm{E}$ type 4 allele and the risk of Alzheimer's disease in late onset families. Science. 1993;261(5123):921-3.

9. Holtzman DM, Bales KR, Tenkova T, Fagan AM, Parsadanian M, Sartorius LJ, et al. Apolipoprotein E isoform-dependent amyloid deposition and neuritic degeneration in a mouse model of Alzheimer's disease. Proc Natl Acad Sci USA. 2000;97(6):2892-7.

10. Tai LM, Bilousova T, Jungbauer L, Roeske SK, Youmans $\mathrm{KL}, \mathrm{Yu} \mathrm{C}$, et al. Levels of soluble apolipoprotein E/amyloid-beta (Abeta) complex are reduced and oligomeric Abeta increased with APOE4 and Alzheimer disease in a transgenic mouse model and human samples. J Biol Chem. 2013;288(8):5914-26.

11. Cruchaga C, Kauwe JS, Nowotny P, Bales K, Pickering $\mathrm{EH}$, Mayo K, et al. Cerebrospinal fluid APOE levels: an endophenotype for genetic studies for
Alzheimer's disease. Hum Mol Genet. 2012;21(20): 4558-71.

12. Martinez-Morillo E, Hansson O, Atagi Y, Bu G, Minthon L, Diamandis EP, et al. Total apolipoprotein $\mathrm{E}$ levels and specific isoform composition in cerebrospinal fluid and plasma from Alzheimer's disease patients and controls. Acta Neuropathol. 2014;127(5):633-43.

13. Kanekiyo T, Xu H, Bu G. ApoE and Abeta in Alzheimer's disease: accidental encounters or partners? Neuron. 2014;81(4):740-54.

14. Safieh M, Korczyn AD, Michaelson DM. ApoE4: an emerging therapeutic target for Alzheimer's disease. BMC Med. 2019;17(1):64.

15. Uddin MS, Kabir MT, Jeandet P, Mathew B, Ashraf GM, Perveen A, et al. Novel anti-Alzheimer's therapeutic molecules targeting amyloid precursor protein processing. Oxid Med Cell Longev. 2020;2020:7039138.

16. Kabir MT, Uddin MS, Mamun AA, Jeandet P, Aleya L, Mansouri RA, et al. Combination drug therapy for the management of Alzheimer's disease. Int J Mol Sci. 2020;21(9):3272.

17. Samieri C, Perier MC, Gaye B, Proust-Lima C, Helmer C, Dartigues JF, et al. Association of cardiovascular health level in older age with cognitive decline and incident dementia. JAMA. 2018;320(7): 657-64.

18. Cui MY, Lin Y, Sheng JY, Zhang X, Cui RJ. Exercise Intervention Associated with Cognitive Improvement in Alzheimer's Disease. Neural Plast. 2018;2018:9234105.

19. Du Z, Li Y, Li J, Zhou C, Li F, Yang X. Physical activity can improve cognition in patients with Alzheimer's disease: a systematic review and metaanalysis of randomized controlled trials. Clin Interv Aging. 2018;13:1593-603.

20. Burns JM, Cronk BB, Anderson HS, Donnelly JE, Thomas GP, Harsha A, et al. Cardiorespiratory fitness and brain atrophy in early Alzheimer disease. Neurology. 2008;71(3):210-6.

21. Morris JK, Vidoni ED, Johnson DK, Van Sciver A, Mahnken JD, Honea RA, et al. Aerobic exercise for Alzheimer's disease: a randomized controlled pilot trial. PLoS ONE. 2017;12(2):e0170547.

22. Kivipelto M, Rovio S, Ngandu T, Kåreholt I, Eskelinen M, Winblad B, et al. Apolipoprotein E epsilon4 magnifies lifestyle risks for dementia: a populationbased study. J Cell Mol Med. 2008;12(6b):2762-71. 
23. Jensen CS, Simonsen AH, Siersma V, Beyer N, Frederiksen KS, Gottrup H, et al. Patients with Alzheimer's disease who carry the APOE epsilon4 allele benefit more from physical exercise. Alzheimers Dement (N Y). 2019;5:99-106.

24. Nichol K, Deeny SP, Seif J, Camaclang K, Cotman $\mathrm{CW}$. Exercise improves cognition and hippocampal plasticity in APOE epsilon4 mice. Alzheimers Dement. 2009;5(4):287-94.

25. Etnier JL, Caselli RJ, Reiman EM, Alexander GE, Sibley BA, Tessier D, et al. Cognitive performance in older women relative to ApoE-epsilon4 genotype and aerobic fitness. Med Sci Sports Exerc. 2007;39(1):199-207.

26. Lautenschlager NT, Cox KL, Flicker L, Foster JK, van Bockxmeer FM, Xiao J, et al. Effect of physical activity on cognitive function in older adults at risk for Alzheimer Disease: a randomized trial. JAMA. 2008;300(9):1027-37.

27. Sanders LMJ, Hortobágyi T, Karssemeijer EGA, Van der Zee EA, Scherder EJA, van Heuvelen MJG. Effects of low- and high-intensity physical exercise on physical and cognitive function in older persons with dementia: a randomized controlled trial. Alzheimers Res Ther. 2020;12(1):28.

28. Smith JC, Nielson KA, Woodard JL, Seidenberg M, Durgerian S, Antuono P, et al. Interactive effects of physical activity and APOE- $\varepsilon 4$ on BOLD semantic memory activation in healthy elders. NeuroImage. 2011;54(1):635-44.

29. Woodard JL, Seidenberg M, Nielson KA, Smith JC, Antuono P, Durgerian S, et al. Prediction of cognitive decline in healthy older adults using fMRI. J Alzheimer's Dis. 2010;21:871-85.

30. Woodard JL, Sugarman MA, Nielson KA, Smith JC, Seidenberg M, Durgerian S, et al. Lifestyle and genetic contributions to cognitive decline and hippocampal structure and function in healthy aging. Curr Alzheimer Res. 2012;9(4):436-46.

31. Smith JC, Nielson KA, Woodard JL, Seidenberg M, Durgerian S, Hazlett KE, et al. Physical activity reduces hippocampal atrophy in elders at genetic risk for Alzheimer's disease. Front Aging Neurosci. 2014;6:61.

32. Deeny SP, Poeppel D, Zimmerman JB, Roth SM, Brandauer J, Witkowski S, et al. Exercise, APOE, and working memory: MEG and behavioral evidence for benefit of exercise in epsilon 4 carriers. Biol Psychol. 2008;78(2):179-87.

33. Deeny SP, Winchester J, Nichol K, Roth SM, Wu JC, Dick $\mathrm{M}$, et al. Cardiovascular fitness is associated with altered cortical glucose metabolism during working memory in $\varepsilon 4$ carriers. Alzheimer's Dement. 2012;8(4):352-6.

34. Stringa N, van Schoor NM, Milaneschi Y, Ikram MA, Del Panta V, Koolhaas CM, et al. Physical activity as moderator of the association between APOE and cognitive decline in older adults: results from three longitudinal cohort studies. J Gerontol A Biol Sci Med Sci. 2020;75(10):1880-6.

35. Rovio S, Kåreholt I, Helkala E-L, Viitanen M, Winblad B, Tuomilehto J, et al. Leisure-time physical activity at midlife and the risk of dementia and Alzheimer's disease. Lancet Neurol. 2005;4(11): 705-11.

36. Chang M, Jonsson PV, Snaedal J, Bjornsson S, Saczynski JS, Aspelund T, et al. The effect of midlife physical activity on cognitive function among older adults: AGES-Reykjavik Study. J Gerontol Ser A. 2010;65A(12):1369-74.

37. Schuit AJ, Feskens EJ, Launer LJ, Kromhout D. Physical activity and cognitive decline, the role of the apolipoprotein e4 allele. Med Sci Sports Exerc. 2001;33(5):772-7.

38. Luck T, Riedel-Heller SG, Luppa M, Wiese B, Köhler $\mathrm{M}$, Jessen $\mathrm{F}$, et al. Apolipoprotein E epsilon 4 genotype and a physically active lifestyle in late life: analysis of gene-environment interaction for the risk of dementia and Alzheimer's disease dementia. Psychol Med. 2014;44(6):1319-29.

39. Podewils LJ, Guallar E, Kuller LH, Fried LP, Lopez OL, Carlson $\mathrm{M}$, et al. Physical activity, APOE genotype, and dementia risk: findings from the Cardiovascular Health Cognition Study. Am J Epidemiol. 2005;161(7):639-51.

40. Tan ZS, Spartano NL, Beiser AS, DeCarli C, Auerbach SH, Vasan RS, et al. Physical activity, brain volume, and dementia risk: the Framingham Study. J Gerontol Ser A. 2016;72(6):789-95.

41. Fenesi B, Fang H, Kovacevic A, Oremus M, Raina P, Heisz JJ. Physical exercise moderates the relationship of apolipoprotein E (APOE) genotype and dementia risk: a population-based study. J Alzheimer's Dis. 2017;56:297-303.

42. Murphy MP, LeVine H 3rd. Alzheimer's disease and the amyloid-beta peptide. J Alzheimers Dis. 2010;19(1):311-23.

43. Bateman RJ, Munsell LY, Morris JC, Swarm R, Yarasheski KE, Holtzman DM. Human amyloid- $\beta$ synthesis and clearance rates as measured in cerebrospinal fluid in vivo. Nat Med. 2006;12(7): 856-61. 
44. Mawuenyega KG, Sigurdson W, Ovod V, Munsell L, Kasten T, Morris JC, et al. Decreased clearance of CNS beta-amyloid in Alzheimer's disease. Science (New York, NY). 2010;330(6012):1774.

45. Karran E, Mercken M, Strooper BD. The amyloid cascade hypothesis for Alzheimer's disease: an appraisal for the development of therapeutics. Nat Rev Drug Discovery. 2011;10(9):698-712.

46. Ambrée O, Leimer U, Herring A, Görtz N, Sachser N, Heneka MT, et al. Reduction of amyloid angiopathy and Abeta plaque burden after enriched housing in TgCRND8 mice: involvement of multiple pathways. Am J Pathol. 2006;169(2):544-52.

47. Head D, Bugg JM, Goate AM, Fagan AM, Mintun $\mathrm{MA}$, Benzinger $\mathrm{T}$, et al. Exercise engagement as a moderator of the effects of APOE genotype on amyloid deposition. Arch Neurol. 2012;69(5): 636-43.

48. Jeon SY, Byun MS, Yi D, Lee JH, Ko K, Sohn BK, et al. Midlife lifestyle activities moderate APOE $\varepsilon 4$ effect on in vivo Alzheimer's disease pathologies. Front Aging Neurosci. 2020;12:42.

49. Brown BM, Peiffer JJ, Taddei K, Lui JK, Laws SM, Gupta VB, et al. Physical activity and amyloid- $\beta$ plasma and brain levels: results from the Australian Imaging, biomarkers and lifestyle study of ageing. Mol Psychiatry. 2013;18(8):875-81.

50. Bell RD, Winkler EA, Singh I, Sagare AP, Deane R, $\mathrm{Wu} \mathrm{Z}$, et al. Apolipoprotein E controls cerebrovascular integrity via cyclophilin A. Nature. 2012;485(7399):512-6.

51. Jayakumar R, Kusiak JW, Chrest FJ, Demehin AA, Murali J, Wersto RP, et al. Red cell perturbations by amyloid $\beta$-protein. Biochim Biophys Acta (BBA) Gener Subjects. 2003;1622(1):20-8.

52. Piccarducci R, Daniele S, Fusi J, Chico L, Baldacci F, Siciliano $G$, et al. Impact of ApoE polymorphism and physical activity on plasma antioxidant capability and erythrocyte membranes. Antioxidants (Basel). 2019;8(11):538.

53. El-Amouri SS, Zhu H, Yu J, Marr R, Verma IM, Kindy MS. Neprilysin: an enzyme candidate to slow the progression of Alzheimer's disease. Am J Pathol. 2008;172(5):1342-54.

54. Ebrahimi K, Majdi A, Baghaiee B, Hosseini SH, Sadigh-Eteghad S. Physical activity and beta-amyloid pathology in Alzheimer's disease: A sound mind in a sound body. EXCLI J. 2017;16:959-72.

55. Miners JS, Van Helmond Z, Chalmers K, Wilcock G, Love S, Kehoe PG. Decreased expression and activity of neprilysin in Alzheimer disease are associated with cerebral amyloid angiopathy. J Neuropathol Exp Neurol. 2006;65(10):1012-21.

56. Del Campo M, Stargardt A, Veerhuis R, Reits E, Teunissen CE. Accumulation of BRI2-BRICHOS ectodomain correlates with a decreased clearance of $\mathrm{A} \beta$ by insulin degrading enzyme (IDE) in Alzheimer's disease. Neurosci Lett. 2015;589:47-51.

57. Moore KM, Girens RE, Larson SK, Jones MR, Restivo $\mathrm{JL}$, Holtzman DM, et al. A spectrum of exercise training reduces soluble $A \beta$ in a dose-dependent manner in a mouse model of Alzheimer's disease. Neurobiology of Disease. 2016;85:218-24.

58. Kim J, Basak JM, Holtzman DM. The role of apolipoprotein E in Alzheimer's disease. Neuron. 2009;63(3):287-303.

59. Zhu T-B, Zhang Z, Luo P, Wang S-S, Peng Y, Chu $\mathrm{S}-\mathrm{F}$, et al. Lipid metabolism in Alzheimer's disease. Brain Res Bull. 2019;144:68-74.

60. Poirier J, Miron J, Picard C, Gormley P, Théroux L, Breitner J, et al. Apolipoprotein E and lipid homeostasis in the etiology and treatment of sporadic Alzheimer's disease. Neurobiol Aging. 2014;35 Suppl 2(Suppl 2):S3-10.

61. Poirier J. Apolipoprotein E, cholesterol transport and synthesis in sporadic Alzheimer's disease. Neurobiol Aging. 2005;26(3):355-61.

62. Rapp A, Gmeiner B, Hüttinger M. Implication of apoE isoforms in cholesterol metabolism by primary rat hippocampal neurons and astrocytes. Biochimie. 2006;88(5):473-83.

63. Hamanaka H, Katoh-Fukui Y, Suzuki K, Kobayashi M, Suzuki R, Motegi Y, et al. Altered cholesterol metabolism in human apolipoprotein E4 knock-in mice. Hum Mol Genet. 2000;9(3):353-61.

64. Lee J-H, Hong S-M, Shin Y-A. Effects of exercise training on stroke risk factors, homocysteine concentration, and cognitive function according the APOE genotype in stroke patients. J Exerc Rehabil. 2018;14(2):267-74.

65. Fuzikawa AK, Peixoto SV, Taufer M, Moriguchi EH, Lima-Costa MF. Association of ApoE polymorphisms with prevalent hypertension in 1406 older adults: the Bambuí Health Aging Study (BHAS). Braz J Med Biol Res. 2008;41(2):89-94.

66. Bernstein MS, Costanza MC, James RW, Morris MA, Cambien F, Raoux S, et al. Physical activity may modulate effects of ApoE genotype on lipid profile. Arterioscler Thromb Vasc Biol. 2002;22(1):133-40.

67. Seip RL, Zoeller RF, Angelopoulos TJ, Salonia J, Bilbie C, Moyna NM, et al. Interactive effects of 
APOE haplotype, sex, and exercise on postheparin plasma lipase activities. J Appl Physiol (1985). 2011;110(4):1021-8.

68. Kloske CM, Wilcock DM. The important interface between apolipoprotein e and neuroinflammation in Alzheimer's disease. Front Immunol. 2020;11(754).

69. Lynch JR, Morgan D, Mance J, Matthew WD, Laskowitz DT. Apolipoprotein E modulates glial activation and the endogenous central nervous system inflammatory response. J Neuroimmunol. 2001;114(1):107-13.

70. Lynch JR, Tang W, Wang H, Vitek MP, Bennett ER, Sullivan PM, et al. APOE genotype and an ApoEmimetic peptide modify the systemic and central nervous system inflammatory response. J Biol Chem. 2003;278(49):48529-33.

71. Soto I, Graham LC, Richter HJ, Simeone SN, Radell JE, Grabowska W, et al. APOE Stabilization by Exercise Prevents Aging Neurovascular Dysfunction and Complement Induction. PLoS Biol. 2015;13(10):e1002279-e.

72. Braskie MN, Boyle CP, Rajagopalan P, Gutman BA, Toga AW, Raji CA, et al. Physical activity, inflammation, and volume of the aging brain. Neuroscience. 2014;273:199-209.

73. Nichol KE, Poon WW, Parachikova AI, Cribbs DH, Glabe CG, Cotman CW. Exercise alters the immune profile in Tg2576 Alzheimer mice toward a response coincident with improved cognitive performance and decreased amyloid. J Neuroinflammation. 2008;5:13.

74. Corlier F, Hafzalla G, Faskowitz J, Kuller LH, Becker JT, Lopez OL, et al. Systemic inflammation as a predictor of brain aging: Contributions of physical activity, metabolic risk, and genetic risk. NeuroImage. 2018;172:118-29.

75. Yun Y-W, Kweon S-S, Choi J-S, Rhee J-A, Lee Y-H, Nam H-S, et al. APOE Polymorphism is associated with c-reactive protein levels but not with white blood cell count: Dong-gu Study and Namwon Study. J Korean Med Sci. 2015;30(7):860-5.

76. Cotman CW, Berchtold NC, Christie L-A. Exercise builds brain health: key roles of growth factor cascades and inflammation. Trends Neurosci. 2007;30(9):464-72.

77. Galle SA, van der Spek A, Drent ML, Brugts MP, Scherder EJA, Janssen JAMJL, et al. Revisiting the role of insulin-like growth factor-I receptor stimulating activity and the apolipoprotein E in Alzheimer's disease. Front Aging Neurosci. 2019;11(20).
78. Sen A, Nelson TJ, Alkon DL. ApoE4 and A $\beta$ Oligomers Reduce BDNF Expression via HDAC Nuclear Translocation. J Neurosci. 2015;35(19):7538-51.

79. Erickson KI, Voss MW, Prakash RS, Basak C, Szabo A, Chaddock L, et al. Exercise training increases size of hippocampus and improves memory. Proc Natl Acad Sci USA. 2011;108(7):3017-22.

80. Coelho FGDM, Vital TM, Stein AM, Arantes FJ, Rueda AV, Camarini R, et al. Acute aerobic exercise increases brain-derived neurotrophic factor levels in elderly with Alzheimer's Disease. J Alzheimer's Dis. 2014;39:401-8.

81. Allard JS, Ntekim O, Johnson SP, Ngwa JS, Bond V, Pinder D, et al. APOE\&4 impacts up-regulation of brain-derived neurotrophic factor after a six-month stretch and aerobic exercise intervention in mild cognitively impaired elderly African Americans: a pilot study. Exp Gerontol. 2017;87(Pt A):129-36.

82. Lange-Asschenfeldt C, Kojda G. Alzheimer's disease, cerebrovascular dysfunction and the benefits of exercise: From vessels to neurons. Exp Gerontol. 2008;43(6):499-504.

83. Zade D, Beiser A, McGlinchey R, Au R, Seshadri S, Palumbo C, et al. Interactive effects of apolipoprotein $\mathrm{E}$ type 4 genotype and cerebrovascular risk on neuropsychological performance and structural brain changes. J Stroke Cerebrovasc Dis. 2010;19(4): 261-8.

84. Bender AR, Raz N. Age-related differences in memory and executive functions in healthy APOE $\varepsilon 4$ carriers: the contribution of individual differences in prefrontal volumes and systolic blood pressure. Neuropsychologia. 2012;50(5):704-14.

85. Caselli RJ, Dueck AC, Locke DEC, Sabbagh MN, Ahern GL, Rapcsak SZ, et al. Cerebrovascular risk factors and preclinical memory decline in healthy APOE $\varepsilon 4$ homozygotes. Neurology. 2011;76(12): 1078-84.

86. Gentile MT, Poulet R, Pardo AD, Cifelli G, Maffei A, Vecchione $C$, et al. $\beta$-Amyloid deposition in brain is enhanced in mouse models of arterial hypertension. Neurobiol Aging. 2009;30(2):222-8.

87. Rodrigue KM, Rieck JR, Kennedy KM, Devous MD Sr, Diaz-Arrastia R, Park DC. Risk factors for $\beta$ amyloid deposition in healthy aging: vascular and genetic effects. JAMA Neurol. 2013;70(5):600-6.

88. Zhang L, Zheng H, Luo J, Li L, Pan X, Jiang T, et al. Inhibition of endothelial nitric oxide synthase reverses the effect of exercise on improving cognitive function in hypertensive rats. Hypertens Res. 2018;41(6):414-25. 
89. Filippini N, Ebmeier KP, MacIntosh BJ, Trachtenberg AJ, Frisoni GB, Wilcock GK, et al. Differential effects of the APOE genotype on brain function across the lifespan. NeuroImage. 2011;54(1): 602-10.

90. Zerbi V, Wiesmann M, Emmerzaal TL, Jansen D, Van Beek M, Mutsaers MPC, et al. Resting-state functional connectivity changes in aging apoE4 and apoE-KO mice. J Neurosci. 2014;34(42): 13963-75.

91. Uchida S, Suzuki A, Kagitani F, Hotta H. Responses of acetylcholine release and regional blood flow in the hippocampus during walking in aged rats. J Physiol Sci. 2006;56(3):253-7.

92. Burdette JH, Laurienti PJ, Espeland MA, Morgan A, Telesford Q, Vechlekar CD, et al. Using network science to evaluate exercise-associated brain changes in older adults. Front Aging Neurosci. 2010;2: 23.
93. van der Kleij LA, Petersen ET, Siebner HR, Hendrikse J, Frederiksen KS, Sobol NA, et al. The effect of physical exercise on cerebral blood flow in Alzheimer's disease. Neuroimage Clin. 2018;20:650-4.

94. Mateo I, Llorca J, Infante J, Rodríguez-Rodríguez E, Fernández-Viadero $\mathrm{C}$, Peña $\mathrm{N}$, et al. Low serum VEGF levels are associated with Alzheimer's disease. Acta Neurol Scand. 2007;116(1):56-8.

95. Salomon-Zimri S, Glat MJ, Barhum Y, Luz I, BoehmCagan A, Liraz O, et al. Reversal of ApoE4-driven brain pathology by vascular endothelial growth factor treatment. J Alzheimers Dis. 2016;53(4): 1443-58.

96. Yun-Hong D, Jie L, Yandong Z, Jose AR, Justin CC, Yuchuan D. Cerebral angiogenesis and expression of angiogenic factors in aging rats after exercise. Curr Neurovasc Res. 2006;3(1):15-23. 